\title{
Primary pulmonary hypertension associated with human immunodeficiency virus infection
}

\author{
Rafael Golpe, Begoña Fernandez-Infante, Sonia Fernandez-Rozas
}

\begin{abstract}
Summary
Several cardiorespiratory diseases can complicate human immunodeficiency virus infection. Primary pulmonary hypertension is a rare clinical disorder which carries a bad prognosis. More than 90 cases of HIV-associated primary pulmonary hypertension have been reported to date. Although its pathogenesis remains unknown, some evidence suggests a possible role for the virus itself in its development. Genetic susceptibility may also be implicated. The clinical and histopathologic features of this entity do not differ from those of classic primary pulmonary hypertension. The diagnosis requires a high degree of clinical suspicion and a careful evaluation to rule out causes of secondary pulmonary hypertension. In addition to supportive measures, anticoagulation and vasodilators have been used to treat this disorder, although sufficient data regarding long-term results with these therapies are lacking.
\end{abstract}

Keywords: pulmonary hypertension; human immunodeficiency virus

\author{
Respiratory Section, University \\ Hospital Marques de Valdecilla, \\ Santander, Spain \\ R Golpe \\ B Fernandez-Infante \\ S Fernandez-Rozas
}

Correspondence to Rafael Golpe, General Pardiñas $6-4^{\circ}, 15701$ Santiago de Compostela,
Spain

Accepted 16 December 1997
Primary pulmonary hypertension (PPH) is a clinical syndrome characterised by a persistent elevation of pulmonary artery pressure (mean pulmonary artery pressure $>25 \mathrm{mmHg}$ at rest, or $>30 \mathrm{mmHg}$ during exercise) with normal pulmonary artery wedge pressure, in the absence of secondary causes. ${ }^{1}$ It is now well recognised that pulmonary hypertension can complicate human immunodeficiency virus (HIV) infection. Since it was first described in $1987,{ }^{2}$ more than 90 patients have been reported worldwide in small series and additional case reports. ${ }^{2-32}$ Because this form of pulmonary hypertension has identical clinical and histopathologic features to those of PPH and its exact pathogenesis is unclear, we will refer to it as 'primary', like most authors, although this designation may be the subject of controversy. The aim of this article is to summarise the present state of knowledge about HIV-associated PPH.

\section{Epidemiology}

The incidence of PPH in HIV-positive individuals is not well known, but may be as high as $0.5 \%$, compared with 1 to 2 cases per million in the general population..$^{33}$ About $55 \%$ of cases reported in the literature are male, while there is a slight female predominance in non-HIV-associated PPH of about 1.7:1. ${ }^{1}$ The greater predominance of males in the general distribution of the risk factors for HIV infection probably accounts for this observation.

\section{Pathogenesis}

HIV-associated PPH was first described in a homosexual male. ${ }^{2}$ However, the following seven reported patients were haemophiliacs. ${ }^{345}$ Because of this, some early reports focused on the possible causative role of treatment with lyophilised low-purity factor VIII. Today, it is clear that the development of pulmonary hypertension is not related to the route of HIV infection. A review of the cases reported in the literature reveals that the risk factor for HIV infection is intravenous drug abuse in about $44 \%$ of patients, homosexual contact in $20 \%$, haemophilia in $9 \%$, blood transfusions in $3 \%$, an HIV-positive mother in $2 \%$, and heterosexual contact in $1-2 \%$. In $13 \%$ of patients the route of infection is not known. ${ }^{2-32}$

There is some controversy about the possible direct role of HIV itself in the pathogenesis of PPH in the HIV-positive population. ${ }^{34}$ The onset of pulmonary hypertension in an experimental murine model of acquired immunodeficiency syndrome suggests a causative role of the HIV in the development of PPH in humans. ${ }^{35}$ Moreover, antiretroviral therapy has been associated with an improvement of the haemodynamic parameters in patients with HIV-associated $\mathrm{PPH}$, providing additional indirect evidence of a pathogenic link between the infection and the development of pulmonary hypertension. ${ }^{34}$ An anecdotal report also establishes a possible relationship between the clinical improvement of a patient and antiretroviral therapy. ${ }^{4}$

The mechanisms responsible for the development of HIV-associated PPH remain unclear. In an animal model, repeated administration of Escherichia coli endotoxin leads to an increase in the pulmonary artery pressure. ${ }^{36}$ However, previous infections are documented in less than $10 \%$ of the reported cases of HIV-related PPH, and recurrent infections are even less common. ${ }^{2-32}$ An HIV-associated vasculitis might be another possible explanation, but only one case of necrotising vasculitis has been reported up to now ${ }^{16}$; this kind of injury is known to be associated with intravenous drug abuse ${ }^{37}$ (although the patient described denied such abuse). PPH seems to develop regardless of the degree of immunosuppression: $29 \%$ of patients for whom $\mathrm{CD} 4^{+}$lymphocytes counts are available have more than $0.4 \times 10^{9} / 1 .^{2-32}$ Altered functions of the endothelium 


\section{PPH: epidemiology}

- incidence in general population: 1-2 cases per million people

- incidence in HIV-infected population (estimated): $0.5 \%$

- male/female ratio in classic PPH: 1:1.7

- male/female ratio in HIV-associated PPH: 1.2:1

Box 1

\section{PPH: pathogenesis}

- some controversy exists regarding the possible direct role of HIV

- there is little evidence supporting the role of opportunistic infections

- the possibility of a HIV-associated vasculitis is not supported by histopathologic findings

- the degree of immunosuppression does not seem to be significant

- altered function of pulmonary endothelium may be implicated, although direct infection of endothelial cells by HIV is unlikely

- one or more growth factors may be implicated

- there are data supporting a genetic susceptibility factor determined by MHC alleles

- some authors have speculated about a pathogenetic role of the $\mathrm{CD} 8 / \mathrm{T}$-cell

Box 2

\section{PPH: histopathology \\ - hypertensive pulmonary arteriopathy is the usual finding; plexogenic pulmonary arteriopathy is the most common form, followed by pulmonary artery medial hypertrophy; thrombotic arteriopathy has been reported once \\ - hypertensive pulmonary venopathy (pulmonary veno-occlusive disease) has been described twice \\ - pulmonary capillary haemangiomatosis has not been reported in HIV+ patients}

Box 3 might be important in the pathogenesis of PPH. Endothelium damage may result in an imbalance between vasoactive mediators and probably promote coagulation abnormalities and vascular remodelling. ${ }^{133}$ This points to the possibility of a direct infection of the pulmonary vascular endothelial cells by HIV; however, Mette et al could not demonstrate direct viral infection of the vascular endothelium using electron microscopy, immunohistochemistry, DNA in situ hybridisation and polymerase chain reaction techniques in patients with HIV-associated PPH. ${ }^{17}$ They did, however, demonstrate intracytoplasmic tubuloreticular structures in the endothelial cells. These inclusions appear to be part of the cell response to injury, and have not been seen in patients with non-HIVassociated PPH. ${ }^{17}$ These findings support the hypothesis of an indirect vascular injury, which could be mediated by lymphokines released in response to HIV infection. ${ }^{17}$

Several growth factors have been implicated in the pathogenesis of PPH.$^{39}$ Ensoli et al found that cells infected by HIV produced Tat protein, which stimulated endothelial cell proliferation in cultures from Kaposi's sarcoma lesions. ${ }^{40}$ Therefore, it has been suggested that the proliferative changes seen in the arteries of patients with HIV-associated PPH could be mediated by a factor similar to Tat protein. ${ }^{17}$

Only a small percentage of HIV-infected patients develop pulmonary hypertension. This supports the existence of an idiosyncratic susceptibility to the development of vascular disease. A recent study suggests that this susceptibility could have a genetic basis and might be determined by major histocompatibility complex alleles, particularly HLA-DR6 and HLA-DR $52 .^{30}$ Of special interest is the reported association between HIV-related $\mathrm{PPH}$ and lymphocytic interstitial pneumonitis. ${ }^{151625}$ There are immunogenetic similarities between patients with HIV-positive PPH and those who develop diffuse infiltrative lymphocytosis syndrome, ${ }^{30}$ which is characterised by the presence of $\mathrm{CD} 8 / \mathrm{T}$ lymphocytosis with visceral lymphocytic infiltration. ${ }^{41}$ This suggests that both entities may be part of a common HLA-DR-determined response to HIV. ${ }^{30}$ A case of PPH in a patient with CD8/T-cell large granulocyte leukaemia that improved dramatically with chemotherapy has recently been reported. ${ }^{38}$ The authors suggested a possible pathogenetic role of the CD8/T-cell in this case and in others, like HIV-associated PPH, with low CD4/CD8 ratios. ${ }^{38}$

\section{Histopathology}

In the past, the pathologic confirmation of $\mathrm{PPH}$ diagnosis required the presence of plexogenic pulmonary arteriopathy, but it is now recognised that there are no specific histopathologic lesions of $\mathrm{PPH} .{ }^{42} \mathrm{PPH}$ is characterised pathologically by three types of lesions: hypertensive pulmonary arteriopathy (which includes plexogenic pulmonary arteriopathy, isolated medial hypertrophy, and thrombotic pulmonary arteriopathy), hypertensive pulmonary venopathy, and pulmonary capillary haemangiomatosis. ${ }^{42}$

Most reports of histopathologic findings in HIV-associated PPH describe typical hypertensive pulmonary arteriopathy lesions. Plexogenic pulmonary arteriopathy is the most common reported subset (about $75 \%$ of cases), similar to the level in patients with non-HIV-related PPH. About $20 \%$ of the reported cases present with pulmonary artery medial hypertrophy, either isolated or associated with intimal fibrosis (medial hypertrophy associated with intimal lesions should be classified as plexogenic pulmonary arteriopathy, even in the absence of plexiform lesions, whose diagnostic and prognostic significance has been overemphasized $^{42}$ ). The third subset of hypertensive pulmonary arteriopathy, thrombotic arteriopathy, has only been reported once. ${ }^{21}$ Hypertensive pulmonary venopathy (pulmonary veno-occlusive disease) has been reported in two cases, one of them associated with plexogenic lesions. ${ }^{1525}$ To our knowledge, pulmonary capillary haemangiomatosis has never been reported in HIV-positive patients.

Other pulmonary histopathologic findings incidentally reported in association with vascular lesions in HIV-related PPH include Kaposi's sarcoma, ${ }^{8}$ interstitial fibrosis, ${ }^{6}$ lymphocytic interstitial pneumonitis or discrete interstitial lymphocytic infiltrates, ${ }^{6151625}$ necrotizing vasculitis, ${ }^{16}$ and infectious pneumonitis. ${ }^{26}$

\section{Clinical presentation and natural history}

Symptoms of HIV-associated PPH do not differ essentially from those of classic PPH. Dyspnoea is the most common presenting symptom, appearing in virtually all cases. Other usual symptoms are those related to right ventricular failure (usually in advanced disease), syncope, chest pain and non-productive cough. 


\section{PPH: clinical manifestations} and natural history

- clinical and haemodynamic characteristics are similar to those of classic PPH

- dyspnoea is the most common symptom; chest pain, syncope, and cough are also frequent

- oedema and ascites usually appear in advanced disease, with right-sided heart failure

- the cause of death is attributable to PPH in about $81 \%$ of cases; right ventricular failure is the most common cause of death

\section{Box 4}

\section{PPH: diagnosis \\ - history and physical examination: search for signs of pulmonary hypertension and evidence of a secondary cause \\ - chest X-ray and ECG are abnormal in more than $80 \%$ of cases \\ - echocardiography can estimate the pulmonary artery pressure and exclude myocardial, valvular or pericardial disease \\ - $\mathrm{V} / \mathrm{Q}$ lung scan is necessary to exclude pulmonary embolism \\ - consider pulmonary angiography if lung scan is inconclusive \\ - lung function tests are useful to exclude airway or pulmonary parenchymal disease \\ - cardiac catheterisation is necessary to confirm the diagnosis and guide therapy \\ - in most cases, lung biopsy is not essential in making a diagnosis \\ - serologic tests do not have much clinical relevance, if not guided by the clinical suspicion of connective tissue disease \\ - other tests may be useful in individual cases (chest CT, sleep studies, hypercoagulable screen, etc)}

Box 5
Petitpretz et al compared patients who had HIV-associated PPH with non-HIV-infected individuals who had classic PPH, in terms of clinical characteristics and haemodynamics. ${ }^{24}$ They found that HIV-positive patients differed significantly from HIV-negative patients only in age (32+/-5 vs $42+/-13$ years, respectively), degree of disability (NYHA class III or IV: $50 \%$ vs $75 \%$, respectively) and level of pulmonary hypertension (mean pulmonary artery pressure $50+/-11$ vs $62+/-15 \mathrm{mmHg}$, respectively). ${ }^{24}$ (The mean pulmonary artery pressure of the patients reported in the literature is $54.5+/-12 \mathrm{mmHg}$.) In this study, the percentage of patients with HIV-associated PPH who responded to vasodilator testing (58\%) is similar to that of patients with classic $\mathrm{PPH} .{ }^{24} \mathrm{An}$ analysis of the articles that report the results of vasodilator challenge in HIV-associated $\mathrm{PPH}$, reveals a similar proportion of responders $(55 \%)$.

The prognosis of patients with HIV-associated PPH is worse than that of HIV-positive individuals without PPH. ${ }^{34}$ The cause of death in these patients is attributable to $\mathrm{PPH}$ in $81 \%$ of cases; the mechanism of death is progressive right ventricle failure in about $76 \%$, and sudden death in $20 \%$. The remaining $4 \%$ die because of other pulmonary hypertension-related complications. ${ }^{2-32}$

\section{Diagnosis}

The symptoms of PPH are not specific, particularly in HIV-infected patients, who have a high prevalence of cardiorespiratory problems. Therefore, a high degree of clinical suspicion is required to establish a clinical diagnosis. Physical examination can reveal signs of pulmonary hypertension (an increase in the pulmonary component of the second heart sound, a right-sided fourth heart sound, a tricuspid regurgitation murmur, etc) or typical right-sided heart failure findings (oedema, ascites, hepatomegaly). The chest X-ray is abnormal in up to $84 \%$ of reported cases. The most common findings are cardiomegaly and prominence of the main pulmonary artery. The electrocardiogram shows abnormalities in up to $89 \%$ of cases. Right axis deviation and right ventricular hypertrophy are typical findings.

When pulmonary hypertension is suspected, the evaluation should include an echocardiogram, which is useful to rule out myocardial dysfunction and valvular or pericardial diseases. Doppler studies can be used to determine the pulmonary artery pressure noninvasively.

Ventilation/perfusion lung scanning is mandatory to rule out pulmonary thromboembolic disease. When the results are inconclusive, pulmonary angiography should be considered.

Lung function testing is an important part of the diagnostic evaluation. Lung function tests are usually normal or show mild restrictive defects, frequently with reduced carbon monoxide diffusing capacity. Peripheral airways obstruction has also been reported in classic PPH. ${ }^{43}$ Additionally, pulmonary hyperinflation without airflow obstruction has been described in a patient with HIV-associated PPH. ${ }^{19}$ However, a similar functional pattern has been reported in HIV-positive patients without $\mathrm{PPH}^{44}$ so that the possibility of a casual association cannot be ruled out. The presence of moderate to severe restriction or obstruction should suggest another diagnosis. ${ }^{1}$ However, it is important to remark that the association between PPH and other pulmonary diseases, like lymphocytic interstitial pneumonitis, has been documented several times. ${ }^{15}{ }^{16} \mathrm{Gas}$ exchange is usually impaired in these patients: when arterial blood gases have been reported, only $44 \%$ of cases had a $\mathrm{pO}_{2}>10 \mathrm{kPa}$. In $33 \%$ of patients the $\mathrm{pO}_{2}$ was $<9 \mathrm{kPa}$ and in $17 \%$ it was $<8 \mathrm{kPa}$.

Serologic studies do not seem to be essential in the diagnostic evaluation of this population. Several autoantibodies have been described in patients with HIV-associated $\mathrm{PPH}^{12}{ }^{34}$ but their clinical and pathogenetic significance is unclear: increased levels of ANA and other autoantibodies have also been reported in HIV-positive patients without $\mathrm{PPH} .{ }^{34}$

Cardiac catheterisation is considered an absolute requirement to confirm the diagnosis of PPH and to guide therapy. ${ }^{1}$ However, in more than $30 \%$ of the cases of HIV-associated PPH reported, the pulmonary haemodynamics have not been invasively measured. This probably reflects some reluctance to manage these patients aggressively.

Lung biopsy is not considered essential in making a diagnosis although it may be useful in certain individual cases, particularly when other pulmonary diseases are present, associated with PPH. Pulmonary hypertension secondary to intravenous drug abuse may be impossible to exclude without a lung biopsy. This kind of pulmonary hypertension is caused by embolisms of foreign particles injected with the drug. In these cases, the lung biopsy shows foreign body granulomatosis with characteristic angiothrombosis. ${ }^{45}$ However, ordinary heroin does not contain enough crystalline debris to induce extensive pulmonary angiothrombosis, so the 


\section{PPH: treatment}

- vasodilators and anticoagulation have been used in this population, although long-term results with regard to survival are not known

- supportive measures include diuretics in the presence of right-sided heart failure and oxygen in hypoxaemic patients

- combination antiretroviral therapy may have beneficial effects on pulmonary hypertension and is recommended by some authors, irrespective of the CD4 count or viral load

Box 6

cause is believed to be repeated injections of solutions derived from tablets or pills; only a very small proportion of drug addicts inject tablet derivatives frequently. ${ }^{24}$ Additionally, there is evidence that these patients can show some response to oral vasodilators, ${ }^{46}$ so that making an accurate diagnosis of this subset of pulmonary hypertension may not have much clinical relevance, as its treatment may be similar to that of PPH. This, however, remains to be confirmed.

Other tests, like chest computed tomography or sleep studies, may be useful in individual cases, if indicated by a history suggestive of an underlying secondary aetiology.

\section{Treatment}

The best therapeutic approach to patients with HIV-associated PPH is not known. Most treatments employed in the reported cases are supportive measures (diuretics and oxygen). Only $35 \%$ and $19 \%$ of patients are treated with anticoagulation and vasodilators, respectively. Such therapies have been found to be related with survival in patients with classic PPH. ${ }^{33}$ The similarities between HIV-associated PPH and classic PPH in terms of clinical, histopathologic and haemodynamic characteristics (including response to vasodilator testing) ${ }^{24}$ suggest that HIV-positive patients who respond to vasodilator challenge may benefit from chronic treatment with vasodilators. Until more data regarding long-term results are available, most clinicians would probably try this therapy in those patients in whom a vasodilator trial is feasible (which may be difficult in polymorbid patients).

Although anticoagulation can have survival advantages in classic PPH, ${ }^{1}$ alveolar haemorrhage (usually associated with infectious pneumonia) occurs with some frequency in immunocompromised patients, and its clinical impact is uncertain ${ }^{47}$ So, it is conceivable that anticoagulation could exert a harmful effect that exceeds its hypothetical benefits. To our knowledge, no episodes of alveolar haemorrhage in relation to anticoagulation have been reported in HIVassociated PPH.

Other supportive measures that can be employed include diuretics in advanced disease, when there is evidence of right-sided heart failure, and supplemental oxygen in patients with hypoxaemia, which may produce symptomatic improvement.

Finally, it must be noted that some authors recommend initiating combination antiretroviral treatment in all HIV-infected patients with $\mathrm{PPH}$, irrespective of their $\mathrm{CD}^{+}$lymphocyte counts or viral load levels, since this therapy seemed to exert a beneficial effect on the pulmonary hypertension in one study. ${ }^{34}$

12 Aldamiz-Echebaria M, Agud J, Ayensa C, Zubizarreta J. Hipertension pulmonar primaria virus de la inmunodeficiencia humana (letter). Med Clin (Barcelona) 1991;97:199.

13 Reiser P, Opravil M, Pfaltz M, Speich R Reiser P, Opravil M, Pfaltz M, Speich $R$,
Schneider J. Primary pulmonary hypertension and mesangioproliferative glomerulonephritis in HIV infection (abstract). Dtsch Med Wochensch 1992;117:815-8.

14 Piette AM, Legoux B, Gepner P, Chapman A Hypertension arterielle pulmonaire "primitive" associee a l'infection par le VIH Deux observations. Presse Med 1992;21:616-8.

15 Jacques C, Richmond G, Tierney L, Curtis J McKerrow J, Warnock ML. Primary pulmonary hypertension and human immunodeficiency virus infection in a non-hemophiliac man. Hum virus infection in a no
Pathol 1992;23:191-4.

16 Polos PG, Douglas W, Harley RA, Strange C, Sahn SA. Pulmonary hypertension and human immunodeficiency virus infection. Two reports and a review of the literature. Chest 1992;101: 474-8.

17 Mette SA, Palevsky HI, Pietra GG, et al. Primary pulmonary hypertension in association with human immunodeficiency virus infection. A possible viral etiology for some forms of hypertensive pulmonary arteliopathy. Am Rev Rypertensive pulmonary arteli

18 Duchesne N, Gagnon JA, Fouquette B, et al. Primary pulmonary hypertension associated with HIV infection. Can Assoc Radiol f 1993;44: 39-41.

19 Diaz PT, Clanton T. Marked pulmonary function abnormalities in a case of HIV associated pulmonary hypertension. Chest 1993 104:313-5.

20 Mani S, Smith CJ. HIV and pulmonary hypertension: a review. South Med $尹$ 1994;87: 357-62.
21 Heron E; Laaban JP, Capron F, Quieffin J, Brechot JM, Rochemaure J. Thrombotic primary pulmonary hypertension in an HIV+ patient. Eur Heart 7 1994; 15: 394-396.

22 Sala-Blanch X, Fábregas N, Martínez JM, Plaza A. Hipertensión pulmonar primaria en embarazada portadora del virus de la inmunodeficiencia humana (letter). Med Clin (Barcelona) 1994 102:117-8.

23 de Chadarevian JP, Lichner HW, Karmazin N, Pawel BR, Schultz TE. Pulmonary hypertension and HIV infection: new observations and review of the syndrome. Mod Pathol 1994;7:685-9.

24 Petitpretz P, Brenot F, Azarian R, at Pulmonary hypertension in patients with human immunodeficiency virus infection. human immunodeficiency virus infection Comparison with primary pulmon
sion. Circulation 1994;89:2722-7.

25 Ruchelli ED, Nojadera G, Rutstein RM, Rudy B. Pulmonary veno-occlusive disease. Anothe vascular disorder associated with human immunodeficiency virus infection? Arch Pathol Lab Med 1994;118:664-6.

26 Zraik N, Heny I, Setbon O, Cadranel J. Hypertension arterielle pulmonaire d'allure primitive chez un patient seropositif pour le HIV. Rev Pheumol Clin 1994;50:68-70.

27 Weiss JR, Pietra GG, Scharf SM. Primary pulmonary hypertension and the human immunodeficiency virus. Report of two cases and a review of the literature. Arch Intern Med 1995;155:2350-4.

28 Speciale A, Ramundi M, Fabiani F, Fiorucci F Schmid G. Primary pulmonary hypertension in a HIV+ patient. Monaldi Arch Chest Dis 1995;50:451-2.

29 Marcos F, Moreiras JL, Fernández S, Durán A. Un caso de hipertensión pulmonar primaria en paciente portadora del virus de la inmunodeficiencia humane (letter). An Med Interna 1995; 12:408-9. 
30 Morse JH, Barst RJ, Itescu S, et al. Primary pulmonary hypertension in HIV infection. An outcome determined by particular HLA Class II alleles. Am f Respir Crit Care Med 1996;153: 1299-301.

31 Duche A, Ducroix JP, Lafon B, et al. Hypertension artérielle pulmonaire primitive: un mode rare de revelation du SIDA. A propos d'une observation (letter). Rev Med Interne 1996;17: 774-5.

32 Arranz A, Herrera L, Cuadrado LM, Gonzalez A. Hipertensión pulmonar primaria en una paciente con infección por VIH (letter). Rev Clin Esp 1996; 196:61-2.

33 Rubin LJ. Primary pulmonary hypertension. $N$ Engl f Med 1997;336:111-7.

34 Opravil $M$, Pechére $M$, Speich $R$, et al. HIV-associated primary pulmonary hypertension. A case control study. Am $\mathcal{F}$ Respir Crit Care Med 1997;155:990-5.

35 Gillespie MN, Hartsfield CL, O'Connor WN, Cohen DA. Pulmonary hypertension in a murine model of the acquired immunodeficiency syndrome. Am $\mathcal{f}$ Respir Crit Care Med 1994;150:194-9.
36 Meyrick B, Perkett EA, Brigham KL. Inflammation and models of chronic pulmonary hypertension. Am Rev Respir Dis 1987;136:765-7.

37 Citron BP, Halpern M, McCarron M, et al. Necrotizing angitis associated with drug abuse. N Engl f Med 1970;283:1003-11.

38 Rossoff LJ, Genovese J, Coleman M, Dantzker DR. Primary pulmonary hypertension in a patient with $\mathrm{CD} 8 / \mathrm{T}$-cell large granulocyte leukemia. Amelioration by cladribine therapy. Chest 1997;112:551-3.

39 Gossage JR, Christman BW. Mediators of acute and chronic pulmonary hypertension: part II. Semin Resp Care Med 1994;15:453-61.

40 Ensoli B, Barillari G, Salahuddin SZ, Gallo RC, Wong-Staal F. Tat protein of HIV-1 stimulates growth of cells derived from Kaposi's sarcoma lesions of AIDS patients. Nature 1990;345:846.

41 Itescu S, Dalton J, Zhang HZ, Winchester R. Tissue infiltration in a CD8 lymphocytosis syndrome associated with human immunodeficiency virus-1 infection has the phenotypic appearance of an antigenically driven response. f Clin Invest 1993;91:2216-25.
42 Pietra GG. Histopathology of primary pulmonary hypertension. Chest 1994;105(2):2s-6s.

43 Fernandez-Bonetti P, Lupi-Herrera E, Martinez-Guerra ML, Barrios R, Seoane M Sandoval J. Peripheral airways obstruction in idiopathic pulmonary artery hypertension (primary). Chest 1983;83:732-8.

44 Diaz PT, Clanton TL, Pacht ER. Emphysemalike pulmonary disease associated with human immunodeficency virus infection. Ann Intern Med 1992;116:124-8.

45 Tomashefski JE, Hirsch CS. The pulmonary vascular lesions of intravenous drug abuse. Hum Pathol 1980;11:133-45.

46 Farber H, Glauser FL. The effect of oral hydralazine on the pulmonary hemodynamics of patients with pulmonary foreign body granulomatosis. Chest 1982;82:708-12.

47 De Lassence A, Fleury-Feith J, Escudier E, Beaune J, Bernaudin JF, Cordonnier C. Alveolar haemorrhage. Diagnostic criteria and results in 194 immunocompromised hosts. Am $\mathcal{f}$ Respir Crit Care Med 1995;151:157-63.

AMEE welcomes members and non-members to participate in its 1998 Conference which is being organised in collaboration with the Postgraduate Medical School, Prague. The Conference will be of interest to all connected with the field of medical education-teachers, educators, practitioners, students and administrators. An exciting and varied programme of plenaries, short communications, poster sessions and workshops is being compiled, with sessions relevant to undergraduate, postgraduate and continuing medical education.

Experts from Europe, North America and Australia will contribute to the Plenary sessions, the topics for which are:

- Curriculum Planning/Teaching and Learning

- Continuing Medical Education

- Assessment

A programme of social events has been arranged for participants and accompanying persons, to make the most of the sights and sounds of this magical city, famous for its architecture and music.

Submissions for inclusion in the short communications and poster sessions are invited.

To obtain your copy of the Conference Programme and abstract submission form, please contact:

\section{AMEE Office}

Centre for Medical Education

University of Dundee

Tay Park House

484 Perth Road

Dundee DD2 1LR, UK
Tel: $+44(0) 1382631967$

Fax: +44(0)1382645748

Email: p.m.lilley@dundee.ac.uk

http://www.dundee.ac.uk/MedEd/AMEE/ 